\title{
Induced defences in marine and freshwater phytoplankton: a review
}

\author{
Ellen Van Donk • Adrianna Ianora • \\ Matthijs Vos
}

Received: 4 May 2010/Accepted: 27 July 2010/Published online: 18 September 2010

(C) The Author(s) 2010. This article is published with open access at Springerlink.com

\begin{abstract}
Many organisms have developed defences to avoid predation by species at higher trophic levels. The capability of primary producers to defend themselves against herbivores affects their own survival, can modulate the strength of trophic cascades and changes rates of competitive exclusion in aquatic communities. Algal species are highly flexible in their morphology, growth form, biochemical composition and production of toxic and deterrent compounds. Several of these variable traits in
\end{abstract}

Guest editors: H. J. Dumont, J. E. Havel, R. Gulati \& P. Spaak / A Passion for Plankton: a tribute to the life of Stanley Dodson

E. Van Donk $(\varangle)$

Department of Aquatic Ecology, Netherlands Institute of Ecology, NIOO-KNAW, Rijksstraatweg 6,

3631 AC Nieuwersluis, The Netherlands

e-mail: e.vandonk@nioo.knaw.nl

E. Van Donk

Institute of Environmental Biology, University of Utrecht,

Budapestlaan 4, 3584 CD Utrecht, The Netherlands

A. Ianora

Stazione Zoologica ‘Anton Dohrn' of Naples,

Villa Comunale, 80121 Naples, Italy

M. Vos

Department of Ecology \& Ecosystem Modelling, University of Potsdam, Am Neuen Palais 10, 14469 Potsdam, Germany phytoplankton have been interpreted as defence mechanisms against grazing. Zooplankton feed with differing success on various phytoplankton species, depending primarily on size, shape, cell wall structure and the production of toxins and deterrents. Chemical cues associated with (i) mechanical damage, (ii) herbivore presence and (iii) grazing are the main factors triggering induced defences in both marine and freshwater phytoplankton, but most studies have failed to disentangle the exact mechanism(s) governing defence induction in any particular species. Induced defences in phytoplankton include changes in morphology (e.g. the formation of spines, colonies and thicker cell walls), biochemistry (such as production of toxins, repellents) and in life history characteristics (formation of cysts, reduced recruitment rate). Our categorization of inducible defences in terms of the responsible induction mechanism provides guidance for future work, as hardly any of the available studies on marine or freshwater plankton have performed all the treatments that are required to pinpoint the actual cue(s) for induction. We discuss the ecology of inducible defences in marine and freshwater phytoplankton with a special focus on the mechanisms of induction, the types of defences, their costs and benefits, and their consequences at the community level.

Keywords Defenses - Algae $\cdot$ Review $\cdot$ Plankton community $\cdot$ Cyanobacteria $\cdot$ Toxins 


\section{Introduction}

Organisms at lower trophic levels have to deal with a non-trivial risk of being eaten, and the ability to defend themselves against predators is therefore a main driving force in their evolutionary histories (Tollrian, 1995).

Terrestrial plants are well known to have evolved a wide array of chemical and physical defences against the animals that eat them. Such defences allow plants to survive and reproduce in the same area as herbivores. Similar defences also occur in both freshwater and marine habitats even though knowledge in those aquatic systems is more recent.

At first, plant defences were generally assumed to be constitutive, which is always expressed in the plant. However, this view has changed based on evidence that many defences are only induced in the presence of herbivores. Assuming that defences are costly to an organism, one mechanism by which these costs might be reduced is for the organism to activate its defence mechanisms only when predation risk is sensed (Agrawal, 1998). Another way to reduce costs is to rely on primary metabolites such as storage lipids, which are enzymatically transformed after wounding or ingestion, as in the case of diatom oxylipins. Signals for predation risk may come in visual, audio, physical or chemical forms. Since plants generally lack or have poorly developed visual and audio receptors, detecting predators will have to rely on chemical or mechanical cues.

Induced defences that are similar to those in terrestrial plants have also been found in marine plants (Amsler, 2001), as well as freshwater macrophytes (Jeffries, 1990; Bolser \& Hay, 1998; Prusak et al., 2005). In a review about induced defences in marine macroalgae Amsler (2001) stated that numerous macroalgal species produce chemical and morphological defences that deter consumption by herbivores and thereby presumably increase their fitness, but at the time there were few reports demonstrating induction of chemical defence in macroalgae. Since 2001 more studies have reported induced defences, especially in brown and red macroalgae (e.g. Toth et al., 2005; Molis et al., 2006). In most of these studies on induced defences, herbivores triggered the defence (production of secondary metabolites like phlorotannins) by damaging the macroalgae. It is not yet clear whether this is the dominant mode of defence induction or if an induction in unharmed individual seaweeds in the presence of herbivory, as observed by Toth \& Pavia (2000), is more common.

The discovery that defences can be induced in phytoplankton by grazers as well occurred at about the same time in freshwater and marine systems (Hessen \& Van Donk, 1993; Lampert et al., 1994; Wolfe et al., 1996; Miralto et al., 1999). Traditionally, nutrient limitation, competition, predation and abiotic factors were assumed to shape phytoplankton community structure in marine and freshwater ecosystems. Planktonic primary producers are, however, not all defenceless food particles that are easily harvested by their consumers. Instead, a number of phytoplankton taxa have evolved a variety of either constitutive or inducible defence mechanisms against zooplankton grazing. Phytoplankton species may be highly flexible in traits that affect their edibility, through phenotypic plasticity. Such plasticity may involve their morphology, growth form and biochemical composition. Several of these variable traits in phytoplankton have been interpreted as defence mechanisms against grazing. Pelagic phytoplankton employs a wide range of defence strategies to avoid being ingested or, if ingested, to pass unharmed through the grazer's gut. Zooplankton feed with differing success on various phytoplankton species, depending primarily on size, shape, cell wall structure and the production of toxins. The capability of a phytoplankton species to defend itself against herbivores not only has immediate effects on its own survival, but also bears consequences on competition and trophic cascades within the system (Agrawal, 1998; Van der Stap et al., 2007, 2008, 2009; Van Donk, 2006).

In this article we review induced defences in marine and freshwater phytoplankton with the focus on the cues for induction, the types of defences, their costs and benefits, and their consequences at the community level.

\section{Constitutive versus induced defences}

Defences can be fixed or only be activated in times of increased grazing-mediated mortality risk. The evolution of inducible, as opposed to constitutive, defences is favoured when the risk of herbivory is 
unpredictable, when the production of defences involves fitness costs, and when reliable cues to the risk of herbivory are available (Tollrian \& Harvell, 1999). Induced defences provide a relatively versatile form of protection against different predators, allowing prey to phenotypically adapt to multi-predator regimes (Tollrian \& Dodson, 1999). The defence can be tuned to the predator that will represent the highest predation risk, now and/or in the near future. This is especially important when different consumers pose conflicting demands on the algal defensive response. For example, one herbivore could preferably consume small algae whereas another prefers large ones. The best algal response (to make large colonies or stay small and single-celled) would then depend on which of the two herbivores poses the largest predation risk (e.g. Long et al., 2007).

Despite the fact that some machinery is required to actually induce defences, the costs of inducible defences can be low, because defences are only initiated part of the time, when the predator exceeds a certain threshold density. In general, defences are believed to bring about at least some costs. It is beneficial to only make the investment when the predator is present and poses a realistic risk of predation. If there would be no costs, it would pay to have constitutive defences (see Tollrian \& Harvell, 1999); the benefit of the protection could then be permanently enjoyed. In other words, this would represent a 'just to be sure' type of protection that will function at any time. The literature on the costs of (inducible) defences is mixed. Some studies have failed to detect costs in terms of nutrient or energy investment (e.g. Lürling \& Van Donk, 2000), but studies showing that costs can be fairly high are starting to accumulate (Strauss et al., 2002; Cipollini et al., 2003), although most of the work has been done on terrestrial plants rather than on phytoplankton (but see, e.g. Yang et al., 2009). The costs can also be of an ecological nature. For example, one distinct ecological cost of algal colony formation consists of an enhanced sinking rate of colonies, increasing the loss from the euphotic zone (Lürling \& Van Donk, 2000; Verschoor et al., 2009), which negatively affects competitive ability. In planktonic algae, one would expect that colony formation limits photosynthesis and the uptake of nutrients, as it reduces the available surface-per-volume, but these responses have not been easy to measure using growth rate experiments. When the costs are low, they may remain undetected, especially in a relatively high quality 'good world' environment, such as is often provided in the laboratory.

\section{Cues inducing defence in phytoplankton}

We distinguish three main types of induction cues: (i) chemicals released upon mechanical damage alone, in other words products released from lysed cells of the focal algal species that have not been in contact with a herbivore's digestive system, (ii) herbivore-released chemicals that are produced by the herbivore (i.e. chemicals that it also releases in absence of a particular prey species, for instance when it is feeding on completely different prey taxa) and (iii) specific chemical compounds that are feeding-related, i.e. when cells and/or their contents of the focal algal species come into contact with the feeding apparatus and digestive system of the grazer. Below we shortly introduce and discuss each of these cues, also see Tables 1 and 2, where these three cue types are denoted as $\mathrm{M}, \mathrm{H}$ and $\mathrm{F}$.

\section{Cues associated with mechanical damage (M)}

Mechanical damage may not always be a reliable cue for the risk of herbivory. Algal cells may also show lysis in the absence of grazing, for example at the end of algal blooms, and lysis may be primarily associated with the activity of pelagic viruses. However, mechanical damage could be a good indication for grazing risk by herbivores that exhibit 'messy feeding'. This involves mechanical damage to a considerable portion of the algae these grazers come into contact with, which is then lost, or perhaps purposely rejected, before these algae ever make contact with the 'chemical inside' or digestive system of the grazer. Manipulation of less preferred algae at the feeding groove, (by for example cladocerans such as Daphnia) and rejection of some of these algae, could result in mechanical damage to part of the filtered phytoplankton, also to the acceptable edible algal species. Several species of zooplankton are also known to break up filamentous algae or cyanobacteria into smaller pieces, thus releasing at least some of the cell contents into the environment. Copepods tend to pierce algal prey when the cells are large, and it has 
Table 1 Possible biotest results for three different treatments and their meaning in terms of the responsible mechanism( $(s)$ for defence induction

\begin{tabular}{|c|c|c|c|}
\hline $\begin{array}{l}\text { (1) Medium } \\
\text { conditioned by } \\
\text { artificially lysed algae }\end{array}$ & $\begin{array}{l}\text { (2) Medium conditioned by herbivores } \\
\text { of one species that never fed on the } \\
\text { focal algal species }\end{array}$ & $\begin{array}{l}\text { (3) Medium conditioned by herbivores } \\
\text { of one species that only fed on the } \\
\text { focal algal species }\end{array}$ & $\begin{array}{l}\text { Meaning of test } \\
\text { result in terms } \\
\text { of }(\mathrm{M} / \mathrm{H} / \mathrm{F}) \text { : }\end{array}$ \\
\hline \multicolumn{4}{|c|}{ Test result $(-$ or +$)$ for the combination of treatments $(1-3)$} \\
\hline+ & - & + & $\begin{array}{l}\text { M certain } \\
\text { H excluded } \\
\text { F cannot be excluded }\end{array}$ \\
\hline- & + & + & $\begin{array}{l}\text { M excluded } \\
\text { H certain } \\
\text { F cannot be excluded }\end{array}$ \\
\hline- & + & - & $\begin{array}{l}\text { M excluded } \\
\text { H certain } \\
\text { F excluded }\end{array}$ \\
\hline- & - & + & $\begin{array}{l}\text { M excluded } \\
\mathrm{H} \text { excluded } \\
\text { F certain }\end{array}$ \\
\hline+ & + & + & $\begin{array}{l}\text { M certain } \\
\text { H certain } \\
\text { F cannot be excluded }\end{array}$ \\
\hline
\end{tabular}

Mechanical damage is denoted by (M), Herbivore-specific cues are denoted by $(\mathrm{H})$ and Feeding-specific cues by (F). See section 'Cues inducing defense in phytoplankton' in the main text, for a detailed definition of (M, H and F)

been found that they release a large fraction of the dissolved content of pierced algae when these are toxic (Guisande et al., 2002). It is unknown whether the dissolved algal cell contents are chemically changed during this very brief 'piercing contact' with the herbivore. It seems likely that viral-lysed cells and herbivore-damaged (but undigested) cells release compounds of a highly similar chemical profile (Pohnert et al., 2007). It would then be difficult for undamaged algal cells to discriminate between cues from herbivore-mediated mechanical damage and other causes of lysis. Chemical cues associated with mechanical damage can thus be related to the risk of herbivory, but seem to be on the lower end of the reliability spectrum. However, when algal cells of a certain species show massive population-wide lysis, this can certainly be taken as a stress signal (Vardi et al., 2006).

The biotest required to determine whether mechanical damage alone can induce defences in undamaged algae involves adding the solute of damaged cells to undamaged cells of the same species. This may sound trivial (and in terrestrial plant herbivore studies, mechanical damage is one of the standard treatments or controls), but it is rarely done in freshwater or marine research on algae (but see Lampert et al. 1994; Lürling, 1998). It may also be of interest to see whether undamaged cells only respond to conspecifics or also to less closely related damaged algae of different species but the same genus or order. To our knowledge this kind of test has hardly ever been performed yet (but see Lürling, 1998). It is important to know whether such responses exist, to understand inducible defences in a multi-species community context.

\section{Herbivore-specific cues (H)}

In principle, algae could use herbivore-released chemical cues that are not directly related to feeding. For example, if herbivores use sex pheromones or aggregation pheromones, these strictly intra-specific signals could actually be used or 'spied upon' by algae and cyanobacteria. These signals would actually be highly reliable cues for herbivore presence and identity, as such pheromones are $100 \%$ speciesspecific. Any herbivore-specific cue represents a potentially valuable source of information. Many 


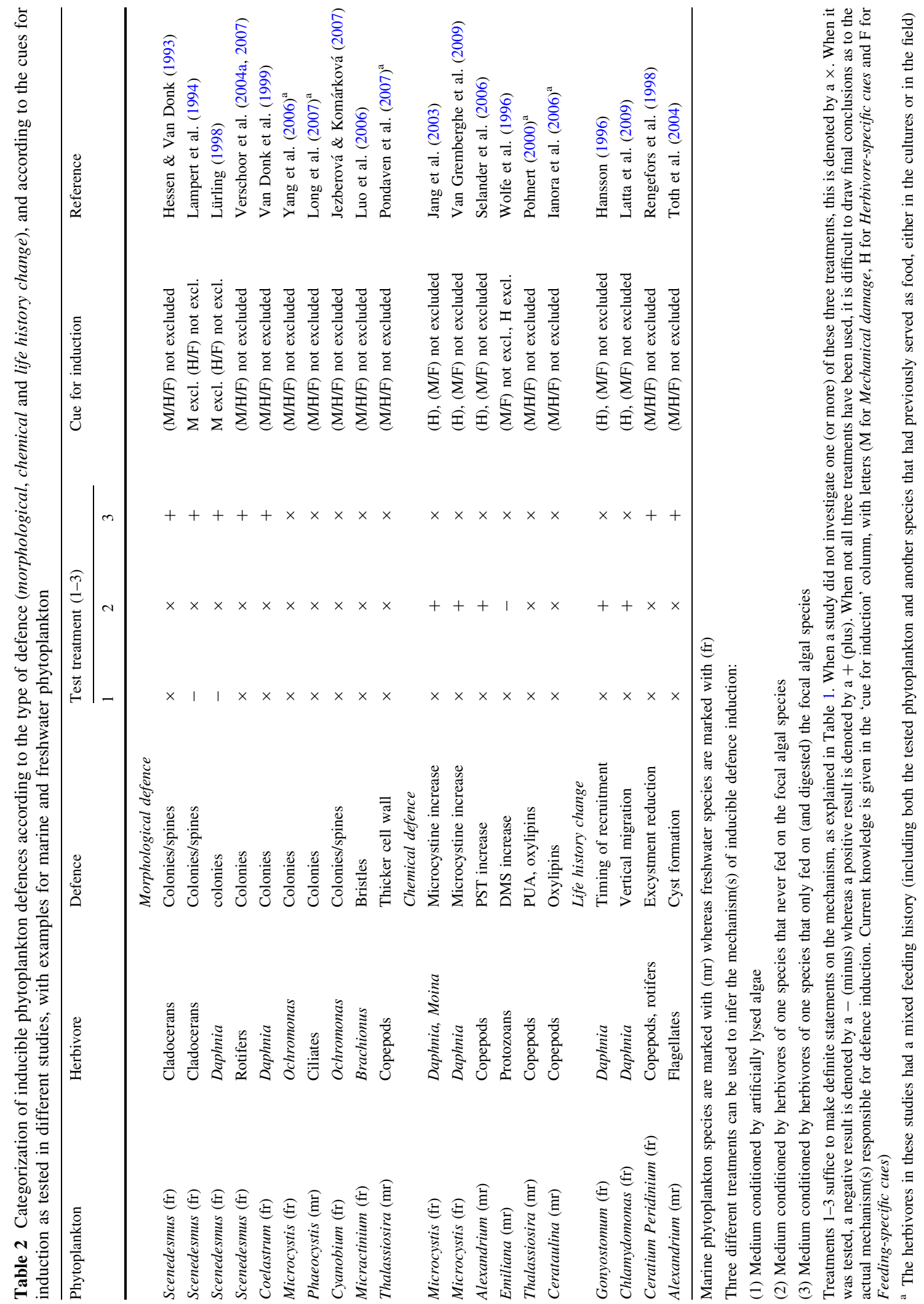


grazers show ontogenetic niche shifts in their diet, and it may pay for algae to respond to herbivorespecific cues, before these herbivores actually start to feed on a particular algal species, i.e. before feedingrelated information becomes available. Herbivorespecific cues may also be used in combination with feeding-specific cues, to respond more accurately in a multi-herbivore environment to not only the fact that algae are eaten, but also to which herbivore might actually be responsible.

A herbivore-specific cue released by a specialist herbivore would represent a highly reliable cue for the risk of herbivory by this species, even though the cue would not be directly associated with herbivory itself. In contrast, a herbivore-specific cue released by a generalist grazer, that opportunistically switches its preferences, would be less informative on the risk of herbivory for any particular algal species. In this case the cue would not reliably indicate, beforehand, if and when this grazer will turn to predate on a particular algal species. However, algae could in theory use infochemical information on their own density in combination with infochemical information on the density of other algae and the generalist, to respond appropriately to the associated predation risk (especially when the generalist reliably switches to the most abundant algal species). The biotest required to determine whether herbivore-specific cues can induce defences in algae, involves adding the medium conditioned by herbivores that have never fed on that species of algae. This may again sound trivial, but this type of biotest has rarely been performed for freshwater or marine algae.

\section{Feeding-specific cues (F)}

Perhaps the most reliable indication for actual predation risk comes from the ambient concentration of feeding-related chemical compounds, where feeding means that digestion of the algae has actually taken place. Feeding-related cues have in the past often been interpreted as 'grazer-released infochemicals' but it is an open question to what extent the prey and/ or the predator are in control of this signal. For the predator it would actually pay not to release any useful information to potential prey, but of course it cannot help releasing at least some compounds following ingestion and digestion of prey. There are some indications that prey are in partial control, with prey containing 'potential signal'-molecules that are activated as a signal when they come into contact with the grazer's digestive system (or its microbial gut flora). Seen this way, grazers are then 'labelled' by their prey (as if tagged with a paint gun, or a cat with a bell), to betray their presence wherever they go (releasing the prey signal molecules by necessity, as they have to digest and egest prey compounds to make a living). The idea of predator labelling was especially well-developed in a study by Stabell et al. (2003). These authors found that the predator failed to induce a defence when it had never eaten the focal prey species, but did induce defences in prey (long) after it had eaten that particular species. The biotest required to determine whether feeding-specific cues can induce defences in algae, involves adding medium in which grazing on the alga of interest has taken place by herbivores that have never previously consumed any other algal species. This is the most often performed type of bio-test in freshwater and marine research, although quite a few studies have used herbivores that have previously consumed algae other than the test alga. The study by Stabell et al. (2003) suggests that consumers can be 'labelled for life', which implies that a starvation period is insufficient to purge the effect of previously consumed algae of another species. However, one should note that this type of test alone (even in its purest form) cannot exclude the possibility that herbivorespecific cues and/or cues based on mechanical damage were (also) involved in defence induction.

In order to disentangle the involved mechanism(s) one needs to actually perform experiments with medium of all of the above-mentioned treatments, conditioned by (1) damage algae of the focal species, (2) herbivores of one species that never fed on the focal algal species, and (3) herbivores of one species (the same species as in treatment 2), that have only grazed on the focal algal species during their entire lifetime.

Some authors have included treatments that involved the addition of dead or live (feeding) herbivores, that had either fed or not fed on the focal algal species before. However, these treatments are not optimally informative. Live feeding herbivores can produce $\mathrm{M}, \mathrm{H}$ and $\mathrm{F}$ cues at the same time, which renders the treatment useless for discrimination amongst these alternatives. There is a wide-spread error in the thinking of the defence induction biotest 
community, that it is useful to add both 'live feeding herbivores' and only the medium conditioned by 'live feeding herbivores'. These are actually relatively uninformative treatments, for the above reason (both can produce $\mathrm{M}, \mathrm{H}$ and $\mathrm{F}$ compounds). Next to this, with the addition of dead herbivores one risks adding the compounds produced when they were still alive (including those produced by messy feeding/mechanical damage), which makes results from such a treatment similarly hard to interpret.

When the three main treatments are combined in a single experiment, one can make definite statements on the mechanism(s) of induction, at least for part of the possible outcomes. A variety of examples is presented in Table 1. Here it suffices to state that induction by mechanical damage (M) alone would yield a score of $(+,-,+)$ for treatments 1-3, whereas induction by a herbivore-specific cue $(\mathrm{H})$ alone would yield a score of $(-,+,+)$ or $(-,+,-)$ and feeding-specific $(F)$ induction would be indicated by $(-,-,+)$.

\section{Morphological defences in phytoplankton}

Large cell size, colonies, spines or silica plates represent morphological traits that may act as a defence against grazing. Depending on the species of grazer, they may effectively prevent ingestion. The hardness of algae also influences their ingestibility (DeMott, 1995). Gelatinous chlorophytes or cells with a thick cell wall may be readily ingested but are poorly digested by freshwater zooplankters such as Daphnia (Porter, 1975; Van Donk \& Hessen, 1993), resulting in depressed zooplankton growth rates (Stutzman, 1995). Some marine haptophytes dinoflagellates and diatoms are also reported to survive gut passage, following ingestion by copepods (Nejstgaard et al., 2007; Kruse et al., 2009).

Hessen \& Van Donk (1993) and Lampert et al. (1994) showed that chemicals released by grazing Daphnia induced the formation of colonies in two species of green algae from the Scenedesmaceae. They showed that single-celled algae formed large four- to eight-celled colonies, and in one of the two species these colonies had longer and more rigid spines. Van Donk et al. (1999) subsequently examined the effect of Daphnia infochemicals on the morphology of fifteen strains of Chlorophyceae, two strains of Bacillariophyceae and three strains of Cyanophyceae. Daphnia-induced colony formation, which was restricted to Chlorophyceae, was in addition to the genus Scenedesmus, also observed in Coelastrum. Lürling et al. (1997) attributed colony formation to feeding activity of Daphnia rather than merely to the presence of daphnids, as starved animals did not induce colony formation in Scenedesmus (Lürling \& Van Donk, 1996). Verschoor et al. (2004a) showed that species of Scenedesmaceae that responded to Daphnia, generally also responded to infochemicals from the rotifer Brachionus calyciflorus, and that colony size could be related to infochemical concentration. However, there was one strain that responded differently to the two grazers, so we cannot conclude there is a single universal 'herbivore' compound or a single 'label' that induced colony formation in these experiments. A first attempt to analyse the infochemicals released by daphnids was made by Van Holthoon et al. (2003). Some years ago, Yasumoto et al. (2005, 2008) reported a major breakthrough with a bioassayguided characterization of infochemicals from a 10-kg sample of Daphnia. After several chromatographic steps, eight aliphatic sulphates that are active at low concentrations $\left(<1 \mathrm{ng} \mathrm{ml}^{-1}\right)$ were isolated and fully characterized. Interestingly, the green alga Scenedesmus reacts to all extracted aliphatic sulphates, although saturated compounds are the most effective. The amphiphilic nature of the infochemicals appears to be more important for activity than specific processes based on ligand-receptor interactions. However, until now there is no proof that these chemicals are released by live daphnids, and comparisons with aliphatic sulphates from smaller grazers such as rotifers have not yet been made.

Induced colony formation could confer grazing resistance against small zooplankters, but could at the same time turn the algae into a better 'bite-size' for larger zooplankton species. In addition, the larger size had a stronger effect on handling times by herbivores than on attack rates of Brachionus rotifers (Verschoor et al., 2007). This means that herbivores spend more time dealing with attacked prey, time in which they could not search for other prey. But colony formation did not effectively prevent eventual ingestion in the Brachionus-Scenedesmus system. It is therefore not as straightforward as in directly 'ingestion-preventing traits' how the observed effect 
on the grazer's functional response (through increased handling time) can act as a defence. These aspects should make us careful when interpreting induced colony formation as a simple anti-herbivore strategy that is always both effective and adaptive. It can be, but does not need to be; it depends on a variety of factors, such as the species of herbivore and the alga's sinking velocity. For example, any benefits of reduced herbivory have to outweigh increased sinking rates out of the euphotic zone, in order for colony formation to be adaptive (Verschoor et al., 2009). DeAngelis et al. (2007) treated the adaptive value of colony formation in more detail, and indicated that the algae should not always all become colonial in the presence of herbivores. There is actually an ideal free distribution (IFD) for the ratio of single-celled algae to colonies, which represents the most effective strategy for algal growth under herbivory (DeAngelis et al., 2007).

A marine example of colony formation is presented by the cosmopolitan phytoplankton genus Phaeocystis (Prymnesiophyceae). The life cycle of Phaeocystis sp. involves an alternation between solitary cells and colonies (Rousseau et al., 1994). Massive blooms of Phaeocystis sp. frequently cause environmental and economic damage to coastal areas (Weisse et al., 1994). Phaeocystis sp. also plays an important role in the global sulphur cycle and in climate regulation due to its high production of dimethyl-sulphoniopropionate (DMSP), a precursor of the climatically active gas dimethylsulphide (DMS) (Liss et al., 1994). Unlike the chain-forming Scenedesmus spp., Phaeocystis sp. colonies are hollow, balloon-like structures with individual cells lying beneath a thin mucous sheet. Colonies of up to a few millimetres in size with only a few thousand individual cells are common in natural Phaeocystis sp. populations (Rousseau et al., 1990), and colonies of $2 \mathrm{~cm}$ in diameter have been recorded in the laboratory (Riegman \& van Boekel, 1996). Phaeocystis colony formation has been interpreted as a defence strategy against small grazers, because large colonies create a size-mismatch problem for small zooplankton (Weisse et al., 1994; Lancelot et al., 1998; Hamm et al., 1999). However, as discussed above for colony formation in Scenedesmus, Phaeocystis, cells may face a dilemma in a more complex food web context, as colony formation will make the cells more vulnerable to larger grazers in the system, such as copepods. Until relatively recently it was unknown how Phaeocystis deals with this dilemma, and to what extent different species of herbivorous zooplankton induce, or fail to induce, colonies. Jakobsen \& Tang (2002) showed that Phaeocystis globosa does form colonies in the absence of grazers, but grazer presence induced a significant increase in the size of these colonies. Mean colony diameter in the grazing treatments was up to 3-fold larger than that in the control; the overall range of colony diameter was also higher in the grazing treatments, indicating that the change in colony diameter was not due to selective grazing on small colonies (Jakobsen $\&$ Tang, 2002). This increase in colony size provided such a strong protection that the grazers subsequently starved and their density declined (Jakobsen \& Tang, 2002). Tang (2003) found that physical contact with grazers was not required to initiate the defensive response. Instead, $P$. globosa colony size increase was found to be stimulated by dissolved chemicals generated by ambient grazing activities. Tang found that various combinations of three species of grazers and four species of phytoplankton in the grazing chambers all resulted in significant, but different extents of colony enlargement in P. globosa in the connected non-grazing chambers (30-300\% larger than the 'grazer-free' control). The author concluded that the signal was non-species-specific (Tang, 2003), but we argue that the signals may have been slightly different for the two dinoflagellate protozoan grazers and the calanoid copepod Temora longicus, whilst having comparable effects on the strain of $P$. globosa (CCMP 1528) that was used in this experiment. Interestingly, much more specific Phaeocystis responses were recently shown by Long et al. (2007), for another strain of P. globosa (CCMP 627), to another species of copepod (Arctia tonsa) and a small ciliate grazer (Euplotes sp.). P. globosa colony formation was suppressed in the presence of the larger grazer, but when small Euplotes grazers attacked this alga, it shifted to the colonial form which was too large to be grazed by these ciliates. These recent experiments on $P$. globosa provided strong evidence that its cells did not only sense that neighbours were being attacked, but also that they 'identified' the attacker and responded with opposing phenotypic shifts depending on the identity of the attacker (Hay, 2009). However, the chemicals responsible for colony formation in this species have not yet been identified. In our view, the 
most important lessons and implications from the above study are that responses can be sophisticated and that differences between strains may play a crucial role in the outcome of species interactions. Different strains of the same algal species clearly showed different responses to different species of small and large grazers. To understand the ecology of phytoplankton defences in the field, we need to learn much more about such diversity and variation in the responses of different genotypes.

Recently it has been demonstrated that grazing by protozoans can also induce colony formation in cyanobacteria. Yang et al. (2006) showed that grazing by the protozoan flagellate Ochromonas sp. induced colony formation in the freshwater cyanobacterial species Microcystis aeruginosa, whereas M. aeruginosa populations in the control and the grazing treatments of the copepod Eudiaptomus graciloides, cladoceran Daphnia magna and rotifer Brachionus calyciflorus were still strongly dominated by single and paired cells, with no colony formation occurring. Colony formation effectively increased the survival of $M$. aeruginosa (Yang et al., 2009).

Not all induced morphological changes involve colony formation. Pondaven et al. (2007) for example reported grazing-induced changes in cell wall silicification in a marine diatom. Grazing-induced silicification may increase the mechanical resistance of the diatom's frustule to copepod mandibules (Hamm et al., 2003). Pondaven et al. (2007) compared changes in cell wall silicification of the marine diatom Thalassiosira weissflogii grown on three different preconditioned media which only differed by the fact that they had contained, either diatoms alone (control medium), non-fed copepods of the species Calanus helgolandicus (starved-copepods medium), or both diatoms and copepods ('diatoms and copepods' medium) before being used for culture experiments. Cells grown in preconditioned media that had contained both diatoms and herbivores were significantly more silicified than diatoms grown in media that contained diatoms alone or starved herbivores. These observations indicate that diatom cell wall silicification is not only a constitutive mechanical protection for the cell, but also a phenotypically plastic trait modulated by grazing-related cues. At present it is still unknown which chemical compound(s) induces this defence. It seems that diatoms have to be attacked and lysed, and perhaps also digested, for the cue to become available. This cue then induces a substantial increase in cell wall silicification in the non-grazed diatoms (this can be seen as a case of 'talking algae'). The silica-plated cell wall acts as an effective defence against grazing.

\section{Chemical defences in phytoplankton}

More than 200 phytoplankton species are known to be toxic or harmful to a range of aquatic organisms. The effects include mass mortality of fish and serious damage to the health of sea mammals (Granéli \& Turner, 2008; Burkholder, 2009). Species that feed higher-up in the food web can be affected by high concentrations of algal chemicals through bio-accumulation. But the relevance of these toxins as an evolved defence against the appropriate herbivores is often unclear and remains vigorously debated. Most of these toxins are always present in the phytoplankton cells and here referred to as constitutive. However, their concentration in the cell may go up following contact with one or more of the abovementioned chemical cues: (i) compounds from mechanically damaged cells, (ii) herbivore-specific chemicals and (iii) feeding-specific compounds. However, not all studies have clearly discriminated between these possibilities, or tested whether the algal cells use a combination. It is also possible that toxins are produced de novo, following contact with the above cues for herbivory risk.

Cyanobacterial blooms have increased in frequency in lakes and freshwater reservoirs around the world, mainly as a result of eutrophication, and the toxins produced by these blooms have been implicated in the deaths of dogs, livestock and waterfowl (Huisman et al., 2005). Cyanobacterial toxins may play a role in prolonging a bloom by inhibiting zooplankton grazing (DeMott et al., 1991) and the growth of competing microbes (Gross et al., 1991). Thus, the toxins may provide a 'swiss armyknife' advantage to cyanobacteria by reducing the effects of herbivory, bacterial fouling and competition (Kearns \& Hunter, 2000).

Jang et al. (2003, 2007) demonstrated that several strains of the freshwater cyanobacterium Microcystis aeruginosa increased their toxin production in response to direct and indirect exposure to large herbivorous 
zooplankton. Just recently Van Gremberghe et al. (2009) demonstrated that these inducible effects in Microcystis are highly strain-specific. However, no induction of toxins was found in response to direct and indirect exposure to the mixotrophic flagellate Ochromonas sp. (Wilken et al., 2010).

A comparable example of induced toxins was found in marine toxic dinoflagellates. Waterborne cues from the marine copepod Acartia tonsa were observed to induce an increase in paralytic shellfish toxin (PST) production in the harmful algal bloom-forming dinoflagellate Alexandrium minutum (Selander et al., 2006). Induced $A$. minutum contained up to 2.5 times more toxins than controls and was more resistant to further copepod grazing. Ingestion of non-toxic alternative prey was not affected by the presence of induced A. minutum. The ability of A. minutum to sense and respond to the presence of grazers by increased PST production, and the associated negative effect on grazers may facilitate the formation of harmful algal blooms in the sea. In further investigations Selander et al. (2008) showed that when A. minutum was grown under nitrate-rich conditions, but not in low nitrate treatments, the presence of waterborne cues from grazers resulted in significantly increased cell-specific toxin content, implying that the magnitude of grazer-induced PST production is directly proportional to the degree of nitrogen availability. Nitrogen availability has repeatedly been reported to be one of the most significant extrinsic factors affecting the cell-specific PST content of Alexandrium spp. This response is grazer-specific, with some species of copepods inducing a higher production of toxins (f.e. up to 20-fold increase in the presence of the copepod Centropages typicus) than others, which may induce no change at all (f.e. Pseudocalanus sp.). This suggests that the specific composition of the zooplankton community will be one of the factors determining the toxin-producing properties of the bloom (Bergkvist et al., 2008).

Induced chemical defences in response to grazing have also been shown for the bloom-forming marine coccolithophorid, Emiliana huxleyi, which produces dimethylsulfoniopropionate (DMSP). Protistan and zooplankton grazers feeding on these cells induced cleavage of DMSP by lyase enzymes into the gas DMS and the feeding deterrent acrylate (Wolfe et al., 1996). DMS released into sea water, and eventually into the atmosphere, can have profound effects on global climate processes. A wide range of organisms at different trophic levels in marine food webs use DMS as a cue for 'biological activity' and are attracted to it (Steinke et al., 2002; Nevitt et al., 2004; Vos et al., 2006; Pohnert et al., 2007). However, since the compound is produced by a great variety of organisms, including bacteria, the signal is not very reliable with respect to the species identity of the producer (Vos et al., 2006).

Diatoms are often the dominant group amongst the oceans' phytoplankton. They produce a variety of chemicals that negatively affect reproductive success in copepods. These chemicals include polyunsaturated aldehydes (PUAs) and other oxylipins (reviewed by Leflaive \& Ten-Hage, 2009; Ianora \& Miralto, 2010). Oxylipins have a range of different functions in algae, higher plants, animals and fungi, which complicates evaluations of the question whether they primarily evolved as a defence (see Flynn \& Irigoien, 2009 for model-based criticism on this hypothesis for a plankton system). Miralto et al. (1999) first isolated PUAs from the diatom Thalassiosira rotula and showed that these compounds were responsible for reduced hatching success and the production of abnormal nauplii (teratogenesis) in copepods. Pohnert (2000) successively showed that when diatoms are damaged during feeding, there is a rapid onset of PUA production seconds after cell disruption, similar to the wound reaction in higher plants (Blee, 2002). PUAs are cleaved from fatty acid precursors by enzymes that are activated within seconds after crushing of cells. Fontana et al. (2007a) measured PUA production and demonstrated that diatom enzymes are active for a substantial period in seawater (up to $40 \mathrm{~min}$ ) thereby enhancing local concentrations of these toxins either in the surrounding water or, if ingested, in the body of grazers. More recently Romano et al. (2010) measured decadienal concentrations spectrophotometrically in a closed vessel and showed that initial levels remained relatively stable for several days, suggesting that local concentrations may be high enough to potentially impact fertilization success and embryonic fitness in marine invertebrates that may be particularly sensitive to these compounds.

The production of PUAs can also be accompanied by the synthesis of other products (collectively termed oxylipins) derived from the lipoxygenase-mediated oxidation of membrane lipids (Fontana et al., 2007b). 
Hence, the negative impact of diatoms is not due to a single class of molecules (i.e. PUAs), as previously believed, but rather to a mixture of compounds produced from the oxidation of fatty acids. Interestingly diatom oxylipins are very similar to those produced by higher flowering plants that are believed to play a pivotal role in plant defence because they act as chemical attractors (e.g. pheromones, pollinator attraction) or alarm signals against herbivore attack (e.g. in tritrophic interactions) and protective compounds (antibacterial, wound healing) (Blee, 2002). Diatom oxylipins also show a high similarity to volatile organic carbons released from brown algae which are suggested to be involved in chemical signalling and pheromone attraction between gametes of different sex (Andreou et al., 2009).

The relative importance of the different compounds may differ per diatom species. For instance, the bloom-forming diatom Cerataulina pelagica released oxylipins that affect copepod reproduction, but not PUAs (Ianora et al., 2008). Oxylipin-associated reproductive failure and poor recruitment are called 'insidious effects', because there is no or little direct effect on adult zooplankter mortality or on their grazing rate. Such effects may restrain copepod cohort size of the next generation, with consequences for food web interactions at that time (Ianora et al., 2004). A larger part of diatom biomass may sink to the ocean floor, with due effects on the benthic community and the associated biogeochemistry. The role in the evolutionary arms race between plants and herbivores of such insidious, as opposed to straightforward toxic effects, is not clear (Miralto et al., 1999). In terrestrial environments, there are many reports of substances produced by plants that interfere with the reproductive capacity of grazing animals and which act as a form of population control. For example, ingestion of certain phytoecdysones inhibits larval growth and development in several species of insects, as well as interferes with the breeding of domestic sheep and some wild bird populations (Robbins et al., 1968). Such anti-herbivore agents may be common in both aquatic and terrestrial habitats even though most of the attention has traditionally focussed on feeding deterrents and poisoning compounds.

Carotenuto et al. (2005) also found effects of these compounds in the freshwater cladoceran Daphnia pulicaria. Egg hatching success was reduced in daphnids that had consumed diets of the PUAproducing diatom Fragilaria sp., and in vitro tests indicated a dose-dependent inhibition for aldehydes. Daphnia and other freshwater pelagic grazers such as the copepods Cyclops and Eudiaptomus have been shown to react to PUAs with reduced swimming activity (Jüttner, 2005). Interpretation of the behavioural effects of oxylipins on freshwater grazers range from repellents and deterrents to attractant foodfinding cues (Jüttner, 2005; Fink et al., 2006).

\section{Changes in life history and behaviour}

Changes in life history and behaviour as defensive response to consumers have not been well studied in the aquatic environment. Most examples are available on the induction of such defences in animals rather than plants (Tollrian \& Harvell, 1999).

Several freshwater algal species may possibly regulate their recruitment rate from sediment depending on the presence or absence of grazers in the water column (Hansson, 1996, 2000). For example, flagellated algae like Gonyostomum semen can use infochemicals released by herbivores to adjust the timing of their recruitment from the 'seed-bank', thereby reducing the exposure to grazing. Induced changes in the life history of algae were observed for the marine alga Alexandrium ostenfeldii. Substances released by parasitic flagellates induced cyst formation and made this alga less vulnerable for the parasites (Toth et al., 2004).

Rengefors et al. (1998) found in laboratory experiments that excystment of the dinoflagellate Ceratium hirundinella occurred at high temperatures irrespective of whether zooplankton exudate was added or not, whereas at intermediate temperatures, excystment was lower if zooplankton exudate was added. Germination of the dinoflagellate Peridinium aciculiferum cysts was lower in the presence of exudate from a zooplankton culture than in controls at all temperatures. Their studies suggest that dinoflagellates use the presence of zooplankton in addition to temperature as a cue to determine when to excyst. Latta et al. (2009) discovered that infochemicals produced by zooplankton (Daphnia) generally increased phototaxis in Chlamydomonas reinhardtii. The adaptive significance of such behavioural changes in natural settings would depend largely on local community composition. 


\section{Consequences at the community level}

Changes in prey morphology, toxicity and behaviour of plankton in response to infochemicals from a potential predator may increase the probability of survival for individual prey, and this may in turn have population-, community- and even ecosystem-wide consequences.

So far, the consequences of inducible defences have mainly been investigated at the level of populations and small communities (Verschoor et al. 2004b; Van der Stap et al., 2006, 2007, 2008, 2009). Vos et al. (2004a) predicted that nutrient enrichment could destabilize aquatic food chains when defences in prey are fixed or absent, whilst such destabilization, the so-called paradox of enrichment, could be absent when prey have inducible defences (Vos et al., 2004a). Verschoor et al. (2004b) empirically tested the predictions by Vos et al. (2004a), using food chains consisting of inducible defended and undefended algae, herbivorous rotifers and carnivorous rotifers. In enriched food chains with undefended algae, they observed large amplitude oscillations over several orders of magnitude, which incidentally resulted in extinction of the top predator. On the other hand, food chains with inducible defended algae stabilized very rapidly, without large amplitude population fluctuations during the initial transient phase. Thus, induced defences prevented strong fluctuations and extinctions of species at higher trophic levels. Vos et al. (2004b) also predicted that inducible defences cause all trophic levels to increase under enrichment. This pattern is consistent with both field and laboratory observations (Vos et al., 2004b). Interestingly, the model analyses by Vos et al. (2004a, b) predicted that inducible defences in algae have a strong effect on community stability, whereas inducible defences in herbivores have a very strong effect on trophic structure, the distribution of biomass across trophic levels. This is exactly what was observed in subsequent experiments with algae, herbivorous rotifers and carnivorous rotifers (Verschoor et al., 2004b; Van der Stap et al., 2007). In this particular plankton system, induced defences prevent ingestion more effectively at the herbivore-carnivore interface than at the algaherbivore interface. These results make clear that one needs to understand the consequences of inducible defences in a multi-trophic level context; defences in algae and grazers may affect different community level processes to a different extent, and there could be synergistic effects of defences at different trophic levels, depending on the particular combination of traits in a particular system.

\section{Discussion and suggestions for future research}

Inducible defences occur across a wide range of taxa, both in primary producers and in their herbivores. Recent studies are starting to show how dynamic, complex and intricate food web interactions really are. Phytoplankton species may show induced changes in morphology, toxicity and life history. A single phenotype may combine different kinds of inducible defences or a combination of induced defences and constitutive defences. The exact combination may be tuned to a variety of cues for predation risk, including feeding-specific, and/or herbivore-specific and/or cell damage-related cues. Moreover, potential grazers of marine and freshwater phytoplankton may also show inducible defences to their own consumers, and they may be phenotypically plastic in their (offensive) response to algal defences (see Agrawal, 2001). Very little is currently known about the community level consequences of inducible defences in complex communities. More work is needed to evaluate such consequences in terms of (1) the relationship between food web structure and the occurrence of inducible defences at different positions within the web, (2) the diversity and proportion of species with inducible defences at each trophic level, (3) the different reliabilities (as a predictor of predation risk) of the different cues for defence induction that are used by phytoplankton species, as mentioned in Tables 1 and 2 and (4) the evolution of inducible defences in a complex multitrophic food web context. We suggest that future research takes on such complexity by further integrating ecological issues of defence inducibility, species diversity and food web structure with evolutionary questions such as those that have been raised by a number of authors (Parejko \& Dodson, 1991; Tollrian \& Dodson, 1999; Tollrian \& Harvell, 1999; Szulkin et al., 2006; Flynn \& Irigoien, 2009). We further see an important role for both natural environmental factors 
and man-induced changes as mechanisms to be studied in aquatic ecosystems, as these may have synergistic effects (Hanazato \& Dodson, 1995; Lürling \& Scheffer, 2007). Most of the chemicals synthesized are present in very low concentrations, and their activity may be very sensitive to environmental toxicants or to chemical stressors including ocean acidification and increased temperatures that can alter the production and degradation of these products (Vogt et al., 2008).

More in general we need a gradual scaling up of our experiments to richer multi-species systems, as it is becoming more and more clear that the results of simple 2-species experiments cannot be extrapolated to more complex natural communities (Kratina et al., 2007). We are currently working on a new generation of models that more accurately capture this complexity, also in an evolutionary context. All of these advances depend on solid knowledge about the actual mechanism of defence induction in marine and freshwater phytoplankton. Our Table 2 shows that very few studies have completely resolved which cues are responsible for defence induction, even in the most well-studied systems available. Our Table 1 provides the three treatments that would help future studies to make more definite statements on the actual mechanisms of phytoplankton defence induction.

Open Access This article is distributed under the terms of the Creative Commons Attribution Noncommercial License which permits any noncommercial use, distribution, and reproduction in any medium, provided the original author(s) and source are credited.

\section{References}

Agrawal, A. A., 1998. Induced responses to herbivory and increased plant performance. Science 279: 1201-1202.

Agrawal, A. A., 2001. Ecology - phenotypic plasticity in the interactions and evolution of species. Science 294: 321-326.

Amsler, C. D., 2001. Induced defenses in macroalgae: the herbivore makes a difference. Journal of Phycology 37: 353-356.

Andreou, A., F. Brodhun \& I. Feussner, 2009. Biosynthesis of oxylipins in non-mammals. Progress in Lipid Research 48: $148-170$.

Bergkvist, J., E. Selander \& H. Pavia, 2008. Induction of toxin production in dinoflagellates: the grazer makes a difference. Oecologia 156: 147-154.

Blee, E., 2002. Impact of phyto-oxylipins in plant defense. Trends in Plant Science 7: 315-321.
Bolser, R. C. \& M. E. Hay, 1998. A field test of inducible resistance to specialist and generalist herbivores using the water lily Nuphar luteum. Oecologia 116: 143153.

Burkholder, J. M., 2009. Harmful algal blooms. In Likens, G. E. (ed.), Encyclopedia of Inland Waters. Elsevier, New York: 264-285.

Carotenuto, Y., T. Wichard, G. Pohnert \& W. Lampert, 2005. Life-history responses of Daphnia pulicaria to diets containing freshwater diatoms: effects of nutritional quality versus polyunsaturated aldehydes. Limnology and Oceanography 50: 449-454.

Cipollini, D., C. B. Purrington \& J. Bergelson, 2003. Costs of induced responses in plants. Basic and Applied Ecology 4: 79-89.

DeAngelis, D. L., M. Vos, W. M. Mooij \& P. A. Abrams, 2007. Feedback effects between the food chain and induced defense strategies. In Rooney, N., K. S. McCann \& D. L. G. Noakes (eds), From Energetics to Ecosystems: The dynamics and Structure of Ecological Systems. Springer: 213-235.

DeMott, W. R., 1995. The influence of prey hardness on Daphnia's selectivity for large prey. Hydrobiologia 307 : 127-138.

DeMott, W. R., Q. X. Zhang \& W. W. Carmichael, 1991. Effects of toxic cyanobacteria and purified toxins on the survival and feeding of a copepod and 3 species of Daphnia. Limnology and Oceanography 36: 13461357.

Fink, P., E. von Elert \& F. Juttner, 2006. Volatile foraging kairomones in the littoral zone: attraction of an herbivorous freshwater gastropod to algal odors. Journal of Chemical Ecology 32: 1867-1881.

Flynn, K. J. \& X. Irigoien, 2009. Aldehyde-induced insidious effects cannot be considered as a diatom defence mechanism against copepods. Marine Ecology Progress Series 377: 79-89.

Fontana, A., G. d'Ippolito, A. Cutignano, G. Romano, N. Lamari, A. M. Gallucci, G. Cimino, A. Miralto \& A. Ianora, 2007a. LOX-induced lipid peroxidation mechanism responsible for the detrimental effect of marine diatoms on zooplankton grazers. ChemBioChem 8: 1810-1818.

Fontana, A., G. d'Ippolito, A. Cutignano, A. Miralto, A. Ianora, G. Romano \& G. Cimino, 2007b. Chemistry of oxylipin pathways in marine diatoms. Pure and Applied Chemistry 79: 481-490.

Granéli, E. \& J. T. Turner, 2008. Ecology of Harmful Algae. Springer-Verlag, Berlin, Heidelberg.

Gross, E. M., C. P. Wolk \& F. Juttner, 1991. Fischerellin, a new allelochemical from the freshwater cyanobacterium Fischerella muscicola. Journal of Phycology 27: 686692.

Guisande, C., M. Frangópulos, Y. Caroteuto, I. Maneiro, I. Riveiro \& A. R. Vergara, 2002. Fate of paralytic shellfish poisoning toxins ingested by the copepod Arartia clause. Marine Ecology Progress Series 240: 105-115.

Hamm, C. E., D. A. Simson, R. Merkel \& V. Smetacek, 1999. Colonies of Phaeocystis globosa are protected by a thin but tough skin. Marine Ecology Progress Series 187: 101-111. 
Hamm, C. E., R. Merkel, O. Springer, P. Jurkojc, C. Maier, K. Prechtel \& V. Smetacek, 2003. Architecture and material properties of diatom shells provide effective mechanical protection. Nature 421: 841-843.

Hanazato, T. \& S. I. Dodson, 1995. Synergistic effects of low oxygen concentration, predator kairomone, and a pesticide on the cladoceran Daphnia pulex. Limnology and Oceanography 40: 700-709.

Hansson, L.-A., 1996. Behavioural response in plants: adjustment in algal recruitment induced by herbivores. Proceedings of the Royal Society of London 263: 1241-1244.

Hansson, L.-A., 2000. Synergistic effects of food chain dynamics and induced behavioral responses in aquatic ecosystems. Ecology 81: 842-851.

Hay, M. E., 2009. Marine chemical ecology: chemical signals and cues structure marine populations, communities, and ecosystems. Annual Review of Marine Science 1: 193-212.

Hessen, D. O. \& E. Van Donk, 1993. Morphological changes in Scenedesmus induced by substances released from Daphnia. Archiv für Hydrobiologie 127: 129-140.

Huisman, J., H. C. P. Matthijs \& P. M. Visser, 2005. Harmful Cyanobacteria. Springer, Dordrecht, The Netherlands.

Ianora, A. \& A. Miralto, 2010. Toxigenic effects of diatoms on grazers, phytoplankton and other microbes: a review. Ecotoxicology 19: 493-511.

Ianora, A., A. Miralto, S. A. Poulet, Y. Carotenuto, I. Butttino, G. Romano, R. Cassoti, G. Pohnert, T. Wichard, L. Colluci d'Amato, G. Terrazzano \& V. Smetacek, 2004. Aldehyde suppression of copepod recruitment in blooms of a ubiquitous planktonic diatom. Nature 429: 403-407.

Ianora, A., M. Boersma, R. Casotti, A. Fontana, J. Harder, F. Hoffmann, H. Pavia, P. Potin, S. A. Poulet \& G. Toth, 2006. The H.T. Odum Synthesis Essay. New trends in marine chemical ecology. Estuaries and Coasts 29: 531-551.

Ianora, A., R. Casotti, M. Bastianini, C. Brunet, G. d'Ippolito, F. Acri, A. Fontana, A. Cutignano, J. T. Turner \& A. Miralto, 2008. Low reproductive success for copepods during a bloom of the non-aldehyde-producing diatom Cerataulina pelagica in the North Adriatic Sea. Marine Ecology: An Evolutionary Perspective 29: 399-410.

Jakobsen, H. H. \& K. W. Tang, 2002. Effects of protozoan grazing on colony formation in Phaeocystis globosa (Prymnesiophyceae) and the potential costs and benefits. Aquatic Microbial Ecology 27: 261-273.

Jang, M. H., K. Ha, G. J. Joo \& N. Takamura, 2003. Toxin production of cyanobacteria is increased by exposure to zooplankton. Freshwater Biology 48: 1540-1550.

Jang, M. H., J. M. Jung \& N. Takamura, 2007. Changes in microcystin production in cyanobacteria exposed to zooplankton at different population densities and infochemical concentrations. Limnology and Oceanography 52: 1454-1466.

Jeffries, M., 1990. Evidence of induced plant defences in a pondweed. Freshwater Biology 23: 265-269.

Jezberová, J. \& J. Komárková, 2007. Morphological transformation in a freshwater Cyanobium sp. induced by grazers. Environmental Microbiology 9: 1858-1862.

Jüttner, F., 2005. Evidence that polyunsaturated aldehydes of diatoms are repellents for pelagic crustacean grazers. Aquatic Ecology 39: 271-282.
Kearns, K. D. \& M. D. Hunter, 2000. Green algal extracellular products regulate antialgal toxin production in a cyanobacterium. Environmental Microbiology 2: 291-297.

Kratina, P., M. Vos \& B. R. Anholt, 2007. Species diversity modulates predation. Ecology 88: 1917-1923.

Kruse, S., S. Jansen, S. Krägefsky \& U. B. Kruse, 2009. Gut content analyses of three dominant Antarctic copepod species during an induced phytoplankton bloom EIFEX (European iron fertilization experiment). Marine Ecology 30: 301-312.

Lampert, W., K. O. Rothhaupt \& E. von Elert, 1994. Chemical induction of colony formation in a green alga (Scenedesmus acutus) by grazers (Daphnia). Limnology and Oceanography 39: 1543-1550.

Lancelot, C., M. D. Keller, V. Rousseau, W. O. Smith \& S. Mathot, 1998. Autecology of the marine haptophyte Phaeocystis sp. In Anderson, D. M., A. D. Cembella \& G. M. Hallegraeff (eds), Physiological Ecology of Harmful Algal Blooms. Springer-Verlag, Berlin: 209-224.

Latta, L. C., R. P. O’Donnell \& M. E. Pfrender, 2009. Vertical distribution of Chlamydomonas changes in response to grazer and predator kairomones. Oikos 118: 853-858.

Leflaive, J. \& L. Ten-Hage, 2009. Chemical interactions in diatoms: role of polyunsaturated aldehydes and precursors. New Phytologist 184: 794-805.

Liss, P. S., G. Malin, S. M. Turner \& P. M. Holligan, 1994. Dimethyl sulfide and Phaeocystis - a review. Journal of Marine Systems 5: 41-53.

Long, J. D., G. W. Smalley, T. Barsby, J. T. Anderson \& M. E. Hay, 2007. Chemical cues induce consumer-specific defenses in a bloom-forming marine phytoplankton. Proceedings of the National Academy of Sciences USA 104: 10512-10517.

Luo, W., S. Pflugmacher, T. Pröschold, N. Walz \& L. Krienitz, 2006. Genotype versus phenotype variability in Chlorella and Micractinium (Chlorophyta, Trebouxiophyceae). Protist 157: 315-333.

Lürling, M., 1998. Effect of grazing-associated infochemicals on growth and morphological, development in Scenedesmus acutus (chlorophyceae). Journal of Phycology 34: 578-586.

Lürling, M. \& M. Scheffer, 2007. Info-disruption: pollution and the transfer of chemical information between organisms. Trends in Ecology \& Evolution 22: 374-379.

Lürling, M. \& E. Van Donk, 1996. Zooplankton-induced unicell-colony transformation in Scenedesmus acutus and its effect on growth of herbivore Daphnia. Oecologia 108: 432-437.

Lürling, M. \& E. Van Donk, 2000. Grazer-induced colony formation in Scenedesmus, are there costs to being colonial? Oikos 88: 111-118.

Lürling, M., H. J. De Lange \& E. Van Donk, 1997. Changes in food quality of the green alga Scenedesmus induced by Daphnia infochemicals: biochemical composition and morphology. Freshwater Biology 38: 619-628.

Miralto, A., G. Barone, G. Romano, S. A. Poulet, A. Ianora, G. L. Russo, I. Buttino, G. Mazzarella, M. Laabir, M. Cabrini \& M. G. Giacobbe, 1999. The insidious effect of diatoms on copepod reproduction. Nature 402: 173-176.

Molis, M., J. Korner, Y. W. Ko, J. H. Kim \& M. Wahl, 2006. Inducible responses in the brown seaweed Ecklonia cava: 
the role of grazer identity and season. Journal of Ecology 94: 243-249.

Nejstgaard, J. C., K. W. Tang, M. Steinke, J. Dutz, M. Koski, E. Antajan \& J. D. Long, 2007. Zooplankton grazing on Phaeocystis: a quantitative review and future challenges. Biogeochemistry 83: 147-172.

Nevitt, G. A., K. Reid \& P. Trathan, 2004. Testing olfactory foraging strategies in an Antarctic seabird assemblage. Journal of Experimental Biology 207: 3537-3544.

Parejko, K. \& S. I. Dodson, 1991. The evolutionary ecology of an antipredator reaction norm: Daphnia pulex and Chaoborus americanus. Evolution 45: 1665-1674.

Pohnert, G., 2000. Wound-activated chemical defense in unicellular planktonic algae. Angewandte Chemie International Edition 39: 4352-4354.

Pohnert, G., M. Steinke \& R. Tollrian, 2007. Chemical cues, defense metabolites and the shaping of pelagic interspecific interactions. TREE 22: 198-204.

Pondaven, P., M. Gallinari, S. Chollet, E. Bucciarelli, G. Sarthou, S. Schultes \& F. Jean, 2007. Grazing-induced changes in cell wall silicification in a marine diatom. Protist 158: 21-28.

Porter, K. G., 1975. Viable gut passage of gelatinous green algae ingested by Daphnia. Verhandlungen des Internationalen Verein Limnologie 19: 2840-2850.

Prusak, A. C., J. O’Neal \& J. Kubanek, 2005. Prevalence of chemical defenses among Freshwater plants. Journal of Chemical Ecology 31: 1145-1160.

Rengefors, K., I. Karlsson \& L.-A. Hansson, 1998. Algal cyst dormancy: a temporal escape from herbivory. Proceedings of the Royal Society of London Series B - Biological Sciences 265: 1353-1358.

Riegman, R. \& W. van Boekel, 1996. The ecophysiology of Phaeocystis globosa: a review. Journal of Sea Research 35: 235-242.

Robbins, W. E., J. N. Kaplanis, M. J. Thompson, T. J. Shortino, C. F. Cohen \& S. C. Joyner, 1968. Ecdysones and analogs: effects on development and reproduction of insects. Science 161: 1158-1160.

Romano, G., A. Miralto \& A. Ianora, 2010. Teratogenic effects of diatom metabolites on sea urchin Paracentrotus lividus embryos. Marine Drugs 8: 950-967.

Rousseau, V., S. Mathot \& C. Lancelot, 1990. Calculating carbon biomass of Phaeocystis sp. from microscopic observations. Marine Biology 107: 305-314.

Rousseau, V., D. Vaulot, R. Casotti, V. Cariou, J. Lenz, J. Gunkel \& M. Baumann, 1994. The life cycle of Phaeocystis (Prymnesiophyceae): evidence and hypotheses. Journal of Marine Systems 5: 23-39.

Selander, E., P. Thor, G. Toth \& H. Pavia, 2006. Copepods induce paralytic shellfish toxin production in marine dinoflagellates. Proceedings of the Royal Society of London Series B - Biological Sciences 273: 1673-1680.

Selander, E., G. Cervin \& H. Pavia, 2008. Effects of nitrate and phosphate on grazer-induced toxin production in Alexandrium minutum. Limnology and Oceanography 53: 523-530.

Stabell, O. B., F. Ogbebo \& R. Primicerio, 2003. Inducible defences in Daphnia depend on latent alarm signals from conspecific prey activated in predators. Chemical Senses 28: $141-153$
Steinke, M., G. Malin \& P. S. Liss, 2002. Trophic interactions in the sea, an ecological role for climate relevant volatiles? Journal of Phycology 38: 630-638.

Strauss, S. Y., J. A. Rudgers, J. A. Lau \& R. E. Irwin, 2002. Direct and ecological costs of resistance to herbivory. Trends in Ecology \& Evolution 17: 278-285.

Stutzman, P., 1995. Food quality of gelatinous colonial chlorophytes to the freshwater zooplankters Daphnia pulicaria and Diaptomus oregonensis. Freshwater Biology 34: 149-153.

Szulkin, M., P. Dawidowicz \& S. I. Dodson, 2006. Behavioural uniformity as a response to cues of predation risk. Animal Behaviour 71: 1013-1019.

Tang, K. W., 2003. Grazing and colony size development in Phaeocystis globosa (Prymnesiophyceae): the role of a chemical signal. Journal of Plankton Research 25: 831-842.

Tollrian, R., 1995. Predator-induced morphological defenses: costs, life history shifts, and maternal effects in Daphnia pulex. Ecology 76: 1691-1705.

Tollrian, R. \& S. I. Dodson, 1999. Inducible defenses in cladocera: constraints, costs, and multipredator environments. In Tollrian, R. \& C. D. Harvell (eds), Ecology and Evolution of Inducible Defenses. Princeton University Press, Princeton, USA: 177-202.

Tollrian, R. \& C. D. Harvell, 1999. The Ecology and Evolution of Inducible Defenses. Princeton University Press, Princeton, USA: 383.

Toth, G. B. \& H. Pavia, 2000. Water-borne cues induce chemical defense in a marine alga (Ascophyllum nodosum). Proceedings of the National Academy of Sciences USA 97: 14418-14420.

Toth, G. B., F. Noren, E. Selander \& H. Pavia, 2004. Marine dinoflagellates show induced life-history shifts to escape parasite infection in response to water-borne signals. Proceedings of the Royal Society of London Series B - Biological Sciences 271: 733-738.

Toth, G. B., O. Langhamer \& H. Pavia, 2005. Inducible and constitutive defenses of valuable seaweed tissues: consequences for herbivore fitness. Ecology 86: 612-618.

Van der Stap, I., M. Vos \& W. M. Mooij, 2006. Linking herbivore-induced defences to population dynamics. Freshwater Biology 51: 424-434.

Van der Stap, I., M. Vos \& W. M. Mooij, 2007. Induced defenses in herbivores and plants differentially modulate a trophic cascade. Ecology 88: 2474-2481.

Van der Stap, I., M. Vos, R. Tollrian \& W. M. Mooij, 2008. Inducible defenses, competition and shared predation in planktonic food chains. Oecologia 157: 697-705.

Van der Stap, I., M. Vos, B. W. Kooi, B. T. M. Mulling, E. Van Donk \& W. M. Mooij, 2009. Algal defenses, population stability and the risk of herbivore extinctions: a chemostat model and experiment. Ecological Research 24: 11451153.

Van Donk, E., 2006. Chemical information transfer in freshwater plankton. Ecological Informatics 2: 112-120.

Van Donk, E. \& D. O. Hessen, 1993. Grazing resistance in nutrient-stressed phytoplankton. Oecologia 93: 508511.

Van Donk, E., M. Lürling \& W. Lampert, 1999. Consumerinduced changes in phytoplankton: inducibility, costs, 
benefits, and the impact on grazers. In Tollrian, R. \& C. D. Harvell (eds.), The Ecology, Evolution of Inducible Defenses. Princeton University Press, Princeton, NJ: 89-103.

Van Gremberghe, I., P. Vanormelingen, K. Van der Gucht, A. Mancheva, S. D’Hondt, L. De Meester \& W. Vyverman, 2009. Influence of Daphnia infochemicals on functional traits of Microcystis strains (Cyanobacteria). Hydrobiologia 635: 147-155.

Van Holthoon, F. L., T. A. van Beek, M. Lürling, E. Van Donk $\&$ A. De Groot, 2003. Colony formation in Scenedesmus: a literature overview and further steps towards the chemical characterisation of the Daphnia kairomone. Hydrobiologia 491: 241-254.

Vardi, A., F. Formiggini, R. Casotti, A. de Martino, F. Ribalet, A. Miralto \& C. Bowler, 2006. A stress surveillance system based on calcium and nitric oxide in marine diatoms. PLoS Biology 4: 0411-0419.

Verschoor, A. M., I. van der Stap, N. R. Helmsing, M. Lürling \& E. Van Donk, 2004a. Inducible colony formation within the scenedesmaceae: adaptive responses to infochemicals from two different herbivore taxa. Journal of Phycology 40: 808-814.

Verschoor, A. M., M. Vos \& I. van der Stap, 2004b. Inducible defences prevent strong population fluctuations in bi- and tritrophic food chains. Ecology Letters 7: 11431148 .

Verschoor, A. M., Y. Zadereev \& W. M. Mooij, 2007. Infochemical-mediated trophic interactions between the rotifer Brachionus calyciflorus and its food algae. Limnology and Oceanography 52: 2109-2119.

Verschoor, A. M., O. K. Bekmezci, E. Van Donk \& J. Vijverberg, 2009. The ghost of herbivory past: slow defence relaxation in the chlorophyte Scenedesmus obliquus. Journal of Limnology 68: 327-333.

Vogt, M., M. Steinke, S. Turner, A. Paulino, M. Meyerhofer, U. Riebesell, C. LeQuere \& P. Liss, 2008. Dynamics of dimethylsulphoniopropionate and dimethylsulphide under different $\mathrm{CO}_{2}$ concentrations during a mesocosm experiment. Biogeosciences 5: 407-419.

Vos, M., B. W. Kooi, D. L. DeAngelis \& W. M. Mooij, 2004a. Inducible defences and the paradox of enrichment. Oikos 105: 471-480.

Vos, M., A. M. Verschoor, B. W. Kooi, F. L. Wäckers, D. L. DeAngelis \& W. M. Mooij, 2004b. Inducible defenses and trophic structure. Ecology 85: 2783-2794.

Vos, M., L. E. M. Vet, F. L. Wäckers, J. J. Middelburg, W. H. van der Putten, W. M. Mooij, C. H. R. Heip \& E. Van Donk, 2006. Infochemicals structure marine, terrestrial and freshwater food webs: implications for ecological informatics. Ecological Informatics 1: 23-32.

Weisse, T., K. Tande, P. Verity, F. Hansen \& W. Gieskes, 1994. The trophic significance of Phaeocystis blooms. Journal of Marine Systems 5: 67-79.

Wilken, S., S. Wiezer, J. Huisman \& E. Van Donk, 2010. Microcystins do not provide anti-herbivore defence against mixotrophic flagellates. Aquatic Microbiology Ecology 59: 207-216.
Wolfe, G. V., V. Gordon \& M. Steinke, 1996. Grazingactivated production of dimethyl sulfide (DMS) by two clones of Emiliania huxleyi. Limnology and Oceanography 41: 1151-1160.

Yang, Z., F. X. Kong, X. L. Shi \& H. S. Cao, 2006. Morphological response of Microcystis aeruginosa to grazing by different sorts of zooplankton. Hydrobiologia 563: 225-230.

Yang, Z., F. X. Kong, Z. Yang, M. Zhang, Y. Yu \& S. Q. Qian, 2009. Benefits and costs of the grazer-induced colony formation in Microcystis aeruginosa. Annales de Limnologie - International Journal of Limnology 45: 203-208.

Yasumoto, K., A. Nishigami, M. Yasumoto, F. Kasai, Y. Okado, T. Kusumi \& T. Ooi, 2005. Aliphatic sulfates released from Daphnia induce morphological defense of phytoplankton: isolation and synthesis of kairomones. Tetrahedron Letters 46: 4765-4767.

Yasumoto, K., A. Nishigami, H. Aoi, C. Tsuchihashi, F. Kasai, T. Kusumi \& T. Ooi, 2008. Isolation and absolute configuration determination of aliphatic sulfates as the Daphnia kairomones inducing morphological defense of a phytoplankton - Part 2. Chemical and Pharmaceutical Bulletin 56: 129-132.

\section{Author Biographies}

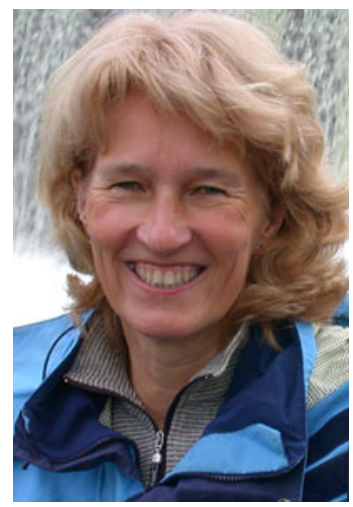

Ellen van Donk graduated from the University of Amsterdam in $1983(\mathrm{PhD}$ in Aquatic Ecology) and visited the University of Michigan (Ann Arbor, USA) for several months in 1981. From 1983 until 1990, she worked as the Head of the Research Department at the Water Board in the State of Utrecht, examining lakes and rivers and applying restoration measures to these waters. Thereafter, she was appointed as an Associate Professor at the Department of Aquatic Ecology and Water Quality Management of the University of Wageningen (1990-1998). Here she continued her research, along with teaching and supervising the research of numerous graduate and undergraduate students. She joined the NIOO-KNAW (Netherlands Institute for Ecology) in 1998 as the Head of the Department of Aquatic Ecology where she continues to examine her main research interests in plankton dynamics and ecology, phytoplankton succession, lake eutrophication and ecosystem stress, and food web studies. From 2000 to 2009 she had a professorship in Limnology at the University of Nijmegen (The Netherlands) on a one-day-a-week basis, which is now continued at the University of Utrecht. In 2001 she also received a visiting professorship in Aquatic Ecology at the University of Oslo (Norway). 


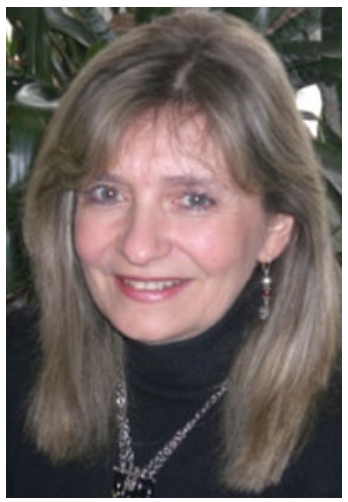

Adrianna Ianora gained her BSc at McGill University, Montreal, Canada, and received her Doctorate in 1980 at the University of Naples, Italy. She has been researcher at the Stazione Zoologica Anton Dohrn of Naples since 1983 and Research Director (Dirigente di Ricerca) since 1998. Her research interests are in the areas of microalgal chemical ecology and copepod ecology, reproduction, development, nutrition and physiology. Her Functional and Evolutionary Biology Laboratory is particularly interested in employing an integrative approach to study plant-herbivore and predator-prey interactions in marine planktonic communities, and on understanding the role of chemical defences in mediating biotic interactions. Currently they are studying the effects of phytoplankton chemical defences, such as polyunsaturated aldehydes produced by several toxic diatom species, on copepod consumer fitness and screening for the presence of new anti-proliferative compounds in dinoflagellates and other microalgal groups. She is the author of more than 70 scientific publications in peer-reviewed journals and co-editor of three books on antarctic and peri-antarctic ecosystems.

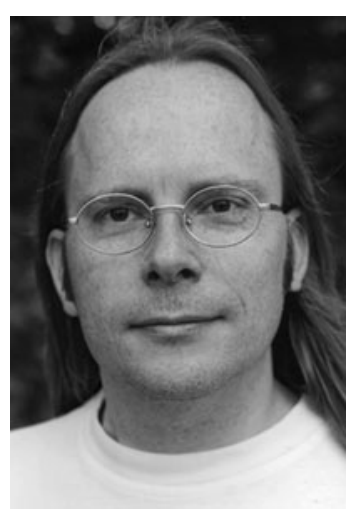

Matthijs Vos has wideranging interests in the mechanisms underlying dynamics and diversity in freshwater, marine and terrestrial communities. He specializes in the roles of infochemicals, (inducible) defences, multitrophic interactions and hidden diversity effects on food webs. Matthijs combines theoretical work with experiments using replicated laboratory communities. He currently holds a research/ teaching position at the University of Potsdam, Germany, in the Department of Ecology and Ecosystem Modeling. 